STRUČNI ČLANAK

\author{
Dr Ivan Janković
}

\title{
PRAVNA PRIRODA UGOVORA O SLEPČOVODSTVU
}

U Okružnom sudu u Kragujevcu je 8. februara 1937. godine održan glavni pretres u krivičnom postupku protiv „slepčovođe i muzikanta“ Tanasija Ilića, optuženog po paragrafu 176, odeljak 1. Krivičnog zakonika Kraljevine Jugoslavije. Taj propis inkriminiše krivično delo izlaganja opasnosti i glasi:

Ko kakvo nemoćno lice koje mu je povereno ili o kojem je inače dužan starati se, napusti ili ostavi bez pomoći u prilikama po život ili zdravlje opasnim, kazniće se robijom do pet godina.

Sudski spis ovog predmeta nije sačuvan, ali postoji novinarski izveštaj sa suđenja. ${ }^{1}$ Činjenično stanje bilo je ovo: Optuženi slepčovođa Ilić i slepac ${ }^{2}$ Sreten Lukić (u krivičnom postupku „privatni učesnik“, tj. oštećeni) radili su 11. oktobra 1936. godine u selu Jarmenovcu. ${ }^{3}$ Predveče su krenuli peške u pet kilometara udaljenu varošicu Rudnik, s namerom da sutradan rade na tamošnjem vašaru. Usput se nisu svađali. Kada su došli do Jasenice, pokazalo se da na uobičajenom mestu nema brvna preko koga se reka inače prelazi. Ilić je to saopštio Lukiću i, onako usput, opsovao Jasenicu. Lukić je na to podviknuo „Ne psuj reku, magarče! Reka je od Boga, a ti si od đavola“ i udario Ilića štapom po glavi. Uvređeni slepčovođa je oterao slepca dođavola i rekao mu: „Odo’ ja. A ti zovi Boga u pomoć.“ Lukić je u početku mislio da se njegov vođa šali, ali kako se ovaj nije vraćao, počeo je da zove u pomoć. U daljini je čuo zvuk vodenice i do nje je, spotičući se i udarajući u drveće, došao tek posle dva sata, sav izubijan. Vodeničar ga je izveo na put, gde su ga našli neki ljudi i poveli do Rudnika. U svojoj odbrani, Ilić je tvrdio da se posle nekoliko minuta pokajao i vratio po Lukića, ali ga nije našao. Lukić je to osporavao i sud je Ilićevu odbranu odbacio. Slepčovođa je naveo i da su tempore criminis

Advokat, Beograd

1 Politika, 10. februar 1937. godine, str. 9.

2 Reč „slepac“ se ovde ne koristi u bilo kakvom pežorativnom smislu, već kao tehnički termin. S obzirom na okolnosti i odnose o kojima se govori u ovom tekstu, svaki drugi termin bi zvučao anahrono. Isto važi za reč „slepčovođa“.

3 Danas: Jarmenovci, naselje u opštini Topola sa 563 stanovnika (prema popisu iz 2002. godine). 
obojica bili pijani, što je slepac negirao rečima: „Nismo bili pijani. Popili smo bili koju, samo da bolje idemo." Sud je Ilića oglasio krivim i osudio ga na šest meseci strogog zatvora. Državni tužilac se zadovoljio presudom, a ni osuđeni nije najavio žalbu.

Nas ovde ne zanima krivičnopravni aspekt kragujevačkog suđenja nego ono čime citirani izveštaj doprinosi našem znanju o faktičkom odnosu slepaca i slepčovođa i o pravnoj prirodi tog odnosa. Tradicionalno, od srednjeg veka, a i ranije, osnovni izvor egzistencije većine slepih i slabovidih osoba bila je prošnja, a u nerazvijenim, naročito $u$ afričkim i azijskim zemljama, tako je i danas. Prošnja je mogla biti neposredna: traženje i dobijanje milostinje Boga radi (bogorađenje), a na osnovu nemaštine i nesposobnosti za rad. Ili je mogla biti prikrivena pod vidom prodaje robe ili usluga za kojima nije bilo stvarne potrebe i koje su donatori kupovali iz samilosti. Prodajući na gradskim ulicama sitnice poput šibica i pertli, slepi prosjaci su izigravali zabranu prošnje tamo gde je ova bila kriminalizovana, ali i povećavali samopoštovanje i sopstvenu društvenu prihvatljivost. Istu funkciju je imalo javno muziciranje - pevanje i sviranje - koje bi prolaznici ili slušaoci nagrađivali. U predindustrijskim društvima, epove i balade pronose slepi pevači, od Homera do onih od kojih je Vuk Karadžić zapisivao narodne pesme: „Slijepci radi prošnje idu jednako po svemu narodu od kuće do kuće, i pred svakom kućom ispjevaju po jednu pjesmu, pa onda ištu da im se udijeli, a đe ih ko ponudi, onđe pjevaju i više; a o praznicima idu k namastirima i k crkvama na sabore i na panađure, pa pjevaju po čitav dan." ${ }^{4}$

U svakom slučaju, slepi prosjak je morao da reši problem orijentacije i kretanja u prostoru, kao i prepoznavanja potencijalnih donatora. Jedni su uspevali da se kreću sami, uz pomoć štapa kojim su proveravali postojanje eventualnih prepreka na putu, računajući da će ih donatori sami uočiti i udeliti im milostinju. ${ }^{5}$ Drugi su se oslanjali na pse kao vodiče. Kućni red prve ustanove za slepe, Kenz-Van (Quinze-Vingts = Tri stotine), koju je osnovao francuski kralj Luj IX u Parizu 1254. godine, pominje pse i uslove pod kojima ih pitomci mogu držati. Inače, slepci Kenz-Vana su imali posebnu kraljevsku dozvolu i u prošnju su išli grupno, u pratnji službenika ustanove. ${ }^{6}$ Prema jednom ekstravagantnom tumačenju, današnji carigradski psi-lutalice potomci su vizantijskih pasa koji su, između ostalog, služili kao vodiči slepim prosjacima. ${ }^{7}$

4 Vuk Karadžić, Srpske narodne pjesme I. Sabrana dela, IV, Prosveta, Beograd 1975, str. 567.

5 Takav je, na primer, bio Deda Vesa iz zbirke Bore Stankovića Božji ljudi, Sabrana dela, I,: Prosveta, Beograd 1974, str. 324.

6 Zina Weygand, The blind in French society from the Middle Ages to the century of Louis Braille, Stanford University Press, Stanford 2009, str. 224.

7 Marcus Rautman, Daily life in the Byzantine Empire, Vestport: Greenwood 2006, str. 80 . 
Postoji mnoštvo podrobnih opisa londonskih slepaca iz XIX veka i njihovih pasa. ${ }^{8}$

Treću i najbrojniju grupu slepih prosjaka čine oni koji su za vodiče imali ljude i upravo su oni predmet našeg interesovanja. Motiv slepca i njegovog vođe je bogato zastupljen u književnosti. Novozavetna parabola o slepcu koji vodi slepe ${ }^{9}$ ilustrovana je bezbroj puta - dovoljno je setiti se Brojgelovog istoimenog remek-dela (1568).

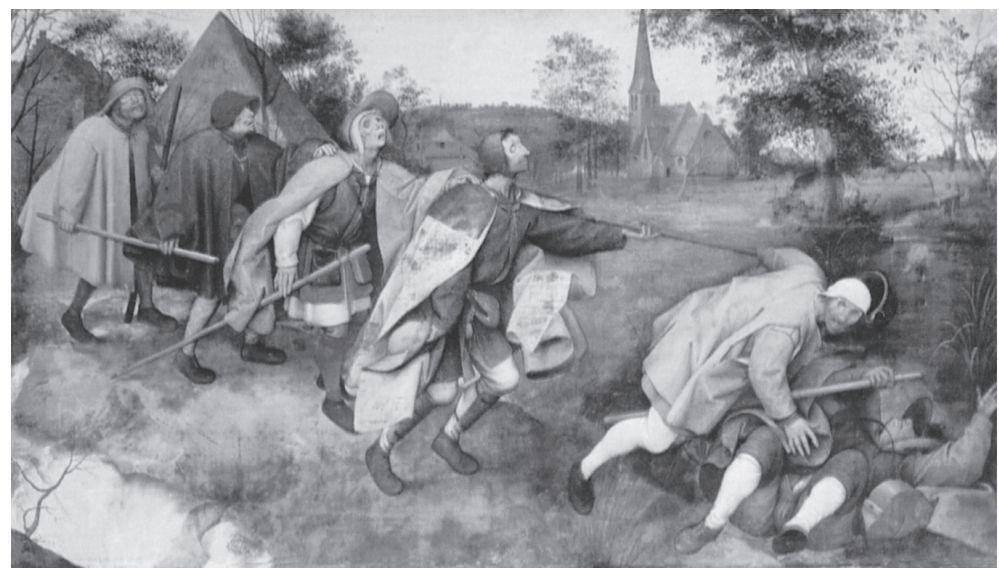

Isti motiv se sreće u slikarstvu i mimo parabole, kao realističan prikaz svakodnevnice u kojoj slepi prosjak svoj posao obavlja uz pomoć slepčovođe. Najstariji sačuvani francuski igrokaz, farsa "Dečak i slepac" (Le garçon et l'aveugle) iz XIII veka, zasniva se na nadmudrivanju malog slepčovođe i škrtog slepca, koji krije isprošeni novac - motiv koji je korišćen u evropskim glumačkim trupama i pozorištima stotinama godina i u stotinama varijacija.

Slepčovođa vodi slepca na mesta na kojima se može očekivati zarada, upućuje ga od koga da traži milostinju (ili to čini u njegovo ime), prima darove (novac ili hranu) ili ih bar nosi umesto slepca i, najzad, sortira i obračunava isprošena dobra. Koliko je važan svaki deo slepčovođinog posla, pokazuje sledeći događaj iz beogradske Knez-Mihailove ulice iz 1909. godine: ${ }^{10}$

Dve slepe odrpane žene, za jednu od kojih se veli da je prosjačenjem kupila kuću, napravile su čitavu zasedu na uglovima kod „Ruskog cara“ i Vasićeve knjižare. Kada je juče pored jedne od njih naišao jedan policajac, ona je, čuvši korake, počela da bogoradi, ali joj je njen vođa trgao ruku uzvikujući: Ne, to je policajac! I taj dečak je to izgovorio tako

8 Npr. Henry Mayhew, London labour and the London poor, I, London: Griffin 1861, naročito str. 397-405.

9 „Slijepac ako slijepca vodi, oba će u jamu pasti“ (Matej, 15:14).

10 Politika, 20. novembar 1909. godine, str. 3. 
ubedljivim glasom, kao da sedi na kasi pred lokalom za koji se plaća ulaz i kao da zna za red, da policajci ne plaćaju ulazak.

Kakav je pravni odnos između slepca i slepčovođe? Iz razmatranja ćemo izostaviti, inače česte, slučajeve kada slepcu u prošnji pomaže sopstveno dete ili drugi član porodice, iako bi se, bez obzira na srodstvo, i taj odnos mogao analizirati sa stanovišta međusobnih pravnih obaveza. Zanemarićemo i slučajeve kada slepac koristi tuđe dete - obično siroče - a za uzvrat mu daje besplatan smeštaj i hranu, ali ne i novac. ${ }^{11}$ Najzad, nećemo se baviti odnosom slepca i slepčovođe ako se on ne zasniva na saglasnosti slobodno izraženih volja obeju strana nego na prinudi ili uceni. Takvi slučajevi spadaju u domen krivičnog prava i zaslužuju posebnu analizu.

Ovde nas zanimaju samo ugovorni odnosi između slepca i slepčovođe, koji uzimaju dva osnovna oblika: (1) slepčovođa za svoj rad dobija od slepca fiksnu naknadu, i tada se radi o nekoj vrsti ugovora o radu, ili (2) slepac i slepčovođa dele dobit stečenu prošnjom, i tada se, bar prima faciae, radi o nekoj vrsti ortakluka. U oba slučaja slepčovođa mora uživati puno poverenje slepe osobe, jer samo on tačno zna koliko je i čega (novca, hrane, robe) prikupljeno prošnjom i u položaju je da dobit ili jedan njen deo prikrije ili utaji. Zbog toga njihov odnos ima jednu jaku crtu fiducijarnog pravnog posla.

Pre nego što pređemo na podrobniju analizu navedenih mogućnosti, jednim primerom ćemo ilustrovati značaj poverenja koje slepa osoba mora imati u svog vođu. U stvarnosti, i slepci i slepčovođe su bili ljudi s društvene margine i grubih naravi, pa poverenje nije bilo lako uspostaviti. Nije jednom bivalo da slepčovođa potkrada, ali i zlostavlja „svog“ slepca. Jedan takav drastičan slučaj dogodio se 1907. godine u Beogradu, a njegova žrtva je bio Joca Jovanović, slepac rodom iz Austro-Ugarske. ${ }^{12}$ Joca je bio član jedne velike „slepačke kompanije“, koja je stanovala u Nebojšinoj ulici, „iza Starog spomenika““ ${ }^{13}$ Kompanija se sastojala od nekoliko slepaca i nekoliko slepčovođa, od kojih je jedan bio i Jocin stanodavac. Upravo taj čovek je poveo Jocu u prošnju u Mirijevo, odakle ga je posle par dana dovezao mrtvog, bar po tvrđenju suseda-očevidaca. Sâm slepčovođa je tvrdio da se Joca u Mirijevu razboleo i da je još bio živ kada su stigli u Beograd, gde je posle jednog sata umro. Međutim, susedi su ispričali i da su „slepčovođe vrlo često tukli nesrećnog Jocu i da im je on često kazivao da se boji da će ga jednog dana ubiti“. Pored toga, „dečko koji je takođe vršio dužnosti slepčovođe i takođe bio u Mirijevu, utekao je od kuće i nigde ga nema“. Kod takvih osnova sumnje, naređena je obdukcija

11 Prema Mayhew, n.d., str. 398, takvi aranžmani su bili skoro pravilo u Londonu 1860ih godina.

12 Prikaz koji sledi dat je na osnovu pisanja Politike, 17. maj 1907. godine, str. 2.

13 „Stari spomenik“ je prvi javni spomenik podignut u Beogradu (1848. godine) i nalazi se u današnjem Karađorđevom parku. Obeležava mesto na kome su sahranjeni ustanici izginuli prilikom osvajanja Beograda 1806. godine. 
Jocinog leša, ali nam njen rezultat, kao ni ishod eventualnog postupka protiv slepčovođe nisu poznati.

Izveštaj sa kragujevačkog suđenja kojim smo započeli ovaj tekst pominje i jedan mehanizam za uspostavljanje poverenja. To je zakletva: „Slepčovođa se pre stupanja na dužnost zaklinje slepcu u svoje oči da neće raditi na prevaru.“ (Kada je optuženi ovo saopštio, iz publike se čulo: „Pa vi to kao državni činovnici!“) Dodatni zaštitni mehanizam je, naravno, raskid ugovora. Iz iskaza na pretresu se vidi da su oba učesnika često menjala partnere kojima nisu bili zadovoljni. Ilić se vajkao: „Tako mi i treba, kad sam se ortačio sa najgorim slepcom. [...] Sto sam slepaca promenio. On je bio najgori, duše mi. [...] I nijednom slepčovođi ne želim da radi sa slepcom kao što je Sreten." Sa svoje strane, Lukić je izjavio da prosjački zanat upražnjava ravno dvadeset godina, „i nisam imao goreg vođu od ove rakijare“. Dakle, ugovor o slepčovodstvu se mogao raskinuti u slučaju nezadovoljstva jedne od ugovornih strana, verovatno bez posebnih formalnosti.

U svom iskazu, slepčovođa je pomenuo „ortačenje“, a reč „ortakluk“ je koristio i jedan član sudskog veća. Kada je Ilić u svojoj odbrani istakao da ga je oštećeni Lukić tukao, sudija mu je dobacio: „Ako te tukao, trebalo je s njim da prekineš ugovor o ortakluku, a ne da ga ostaviš u [...] opasnosti.“ To pokazuje da su ne samo stranke nego i sud na odnos između slepca i slepčovođe gledali kao na vrstu ugovora o ortakluku. Za ovakvo shvatanje ima dobrih razloga. Prvo, oni su radili zajedno. Na početku svog iskaza, Ilić objašnjava da su on i Lukić „radili“ u Jarmenovcu i nameravali da sledećeg dana „rade“ na rudničkom vašaru. Na pitanje suda o kakvom to radu govori, Ilić je spremno objasnio: „Pa naš rad! Znate valjda šta je slepački posao. [...] Muka je to. Svako pseto na slepca zalaje. Pa štrapac, pa svirka. Posao je to, posao." Drugo, oni su delili dobit. Ilić nije hteo da raskida ugovor s Lukićem jer je dobijao „dobar procenat": „Četrdeset od sto, to je dobar procenat. Od sto dinara četrdeset dinara, od sto pita četrdeset pita. Skoro svako drugo parče pogače..." Ukratko, vidi se da su se u ovom slučaju slepac i slepčovođa obavezali da ulože svoj rad radi postizanja zajedničkog cilja, što čini suštinu ortakluka.

Ipak, da li je ugovor o slepčovodstvu samo jedna vrsta ugovora o ortakluku? Prema najopštijoj definiciji, ortakluk je zajednica lica i imovine koja nema svojstvo pravnog lica, što uglavnom odgovara onome što znamo o odnosu Ilića i Lukića, ali i o drugim takvim zajednicama iz Srbije i drugih zemalja. Imovinu ortakluka čini ono što je stečeno zajedničkim poslovanjem, a to je prihod od prošnje. Što se tiče inicijalnih uloga (glavnice), oni su mali ili ih uopšte nema, jer su sredstva neophodna za rad ortaka sasvim skromna. Njih čini, pre svega, prosjačka torba u koju se stavljaju prilozi u naturi i/ili posuda u koju donatori stavljaju novac, a to su stvari veoma male vrednosti. Torba je, bar na Balkanu, simbol prosjačenja u toj meri da su "prosjak" i „torbonoša“ sinonimi. „Ako bio torbonoša, bio majci živ. Ako bio gočobija, ne bio joj živ“, kaže majka kad rodi sina, jer će torbonoša (prosjak) prositi, pa hraniti i sebe i 
nju, a gočobija (bubnjar, muzikant) će otići u svet. ${ }^{14}$ (U navedenoj poslovici se umesto „torbonoša“ mirno može reći „slepčovođa“.) Pored torbe, ortaci bi mogli imati naročita radna odela, ali pošto bi njihova funkcija bila da istaknu siromaštvo nosilaca, i ona bi takođe bila malo vredna ili bezvredna. ${ }^{15} \mathrm{Kod}$ razvijenijih oblika ortakluka radi prošnje, kao što su „kompanije“ slepaca i slepčovođa, sreću se i skuplja sredstva rada - na primer, konji i kola kojima se prosjaci transportuju kako bi eksploatisali što veću teritoriju. Malo je verovatno, međutim, da su takva sredstva zaista ulazila u imovinu ortakluka. Pre će biti da su ona ostajala lična imovina slepčovođa (ili organizatora i vođa kolonije).

Može se naći još sličnosti između ugovorâ o slepčovodstvu i ortakluku. Prvo, i jedan i drugi su kauzalni a ne apstraktni ugovori, jer je osnov obavezivanja (causa) ekspliciran, pošto ortaci imaju pred sobom jasan cilj radi koga zaključuju upravo taj, a ne neki drugi ugovor. Drugo, oni su bilateralni, tj. obostrano obavezni, jer svaki ortak ima da uradi svoj deo posla. Treće, oba ugovora su onerozna, jer su, kao i kod svakog teretnog ugovora, činidbe ugovornih strana međusobno uslovljene. Četvrto, ovi ugovori su ekvivalentni, a ne aleatorni, jer strane u trenutku zaključenja ugovora u celosti znaju svoja prava i obaveze. Peto, to su trajni a ne trenutni ugovori, bez obzira da li je njihovo trajanje kontinuirano ili periodično (npr. prošnja samo na određenim vašarima ili u određeno doba godine). Kao takvi, oni prestaju: protekom vremena na koje su sklopljeni (ako su sklopljeni na određeno vreme); ostvarenjem zajedničkog cilja (npr. ako je cilj ortaka da isprose samo određenu sumu novca); jednostranom izjavom volje (otkazom); ili saglasnošću volja. Najzad, to su lični ugovori, jer se sklapaju intuitu personae i prestaju smrću jednog od ugovarača.

Međutim, postoje i dve bitne razlike zbog kojih, po našem mišljenju, slepčovodstvo nije vrsta ortakluka. Prva se tiče poverenja koje slepac mora imati u slepčovođu i obaveza na strani slepčovođe, koje odatle proističu. Tu se slepčovođa javlja u ulozi fiducijara, a slepac je njegov principal ili fiducijant. Naravno, i među ortacima mora postojati neki minimum ličnog i poslovnog poverenja, ali nijedan ortak nikada ne zavisi od ispravnosti onog drugog u meri u kojoj je to slučaj kod slepčovodstva. I druga razlika je u vezi sa fiducijarnom prirodom slepčovodstva, a tiče se forme. Ugovor o ortakluku je tipičan neformalan ugovor, jer je za njegov nastanak dovoljna saglasnost volja ugovarača o bitnim elementima. Slepčovođa, međutim, kao što smo videli, „stupa na dužnost“ tek kada položi zakletvu da neće varati slepca. Ovaj formalni element, forma ad solemnitatem, ima isključivo zaštitnu (a ne dokaznu)

14 Vuk Karadžić, Srpske narodne poslovice. Sabrana dela, IX. Prosveta, Beograd 1965, s.v.

15 Osim ako su posebno dizajnirana: u Brehtovoj „Operi za tri groša“, Džonatan Jeremija Pičam zapošljava veliki broj prosjaka i ima čitav fundus kostima, smišljenih da izazovu samilost, koje im iznajmljuje. 
funkciju, a ugovor nastaje tek kada je on ispunjen. Zbog toga mislimo da ugovor o slepčovodstvu nije vrsta ugovora o ortakluku nego da je neimenovani ugovor sui generis, koji je kauzalan, bilateralan, onerozan, ekvivalentan, trajan, ličan i formalan.

Ovo što je rečeno važi za ugovore na osnovu kojih slepac i slepčovođa dele dobit stečenu prošnjom. Ostaje da se razmotri pravna priroda odnosa u kome slepac unajmljuje slepčovođu i plaća njegove usluge. Znamo da su takvi aranžmani bili uobičajeni, ali nemamo dovoljno materijala za analizu. Zbog toga se može samo pretpostaviti da je u pitanju vrsta ugovora o radu, kojim se slepčovođa obavezuje da slepca vodi u prošnju i pomaže mu u svemu što se tiče prošnje, a za uzvrat dobija naknadu u novcu ili naturi. Izvesno je da i u ovom slučaju njihov odnos ima jedan poseban element fiducijarnosti, koji je jače izražen nego kod drugih ugovora o radu. 